\title{
IS THE PRACTICE OF DISCONTINUING ASPIRIN THERAPY PRIOR TO DENTAL EXTRACTION CORRECT? A REVIEW
}

\author{
Gunjan Chouksey¹, Jinesh Dugad², Sudip Bhargava ${ }^{3}$, Amrusha Raipure $^{4}$, Sumit Bhargava ${ }^{5}$ \\ ${ }^{1}$ Consultant, Department of Prosthodontics, Fellow Tata Memorial Hospital, Asian Institute of Oncology. \\ ${ }^{2}$ Consultant, Department of Prosthodontics, Fellow Tata Memorial Hospital, Asian Institute of Oncology. \\ ${ }^{3}$ Senior Resident, Department of Anesthesiology, J. J. Medical College, Mumbai. \\ ${ }^{4}$ Assistant Professor, Department of Anesthesia, GMC, Nagpur. \\ ${ }_{5}^{5}$ Associate Professor, Department of Anesthesia, LN Medical College, Bhopal.
}

\section{ABSTRACT}

Aspirin is routinely used drug in patients with cardiac problems. When a patient on aspirin requires dental treatment that has the risk of bleeding, the physician or dental surgeon often advices the patient to stop aspirin for few days. This however can lead to thromboembolic events to recur that may cause myocardial infarction, stroke or even death. The decision to stop the medicine prior to dental extraction or oral surgical procedure is critical.

\section{KEYWORDS}

Dental Surgeon, Thromboembolic Events, Analgesic.

HOW TO CITE THIS ARTICLE: Gunjan Chouksey, Jinesh Dugad, Sudip Bhargava, Amrusha Raipure, Sumit Bhargava. "Is the Practice of Discontinuing Aspirin Therapy Prior to Dental Extraction Correct? A Review." Journal of Evolution of Medical and Dental Sciences 2015; Vol. 4, Issue 102, December 21; Page: 16779-16785, DOI: 10.14260/jemds/2015/2516

\section{INTRODUCTION}

Aspirin (Acetylsalicylic acid/ASA) is a salicylate drug, routinely used as an analgesic, anti-pyretic, anti-inflammatory and anti-platelet agents in a medical practice. ${ }^{1}$ It is known for prevention of arterial thrombosis in both high-risk patients with known occlusive vascular disease and in low-risk healthy patients with no known history of vascular disease. ${ }^{2}$

Patients using aspirin are at a high risk for undergoing invasive dental surgical procedures. This is attributed due to the fact of excessive uncontrolled bleeding, hence the decision regarding continuation, modification or discontinuation of aspirin before dental treatment is critical.3,4 Dental surgeons often asks the patients to stop this drug before dental procedure. ${ }^{5}$ However, stopping this medication may lead to thromboembolic events. $6,7,8,9,10$ to recur causing myocardial infarction, stroke or even death.11,12,13 It is important for the dental practitioner to weigh the risk of clinically significant bleeding from an invasive procedure against the risks associated with an alteration in the dose of aspirin. . $^{3,10}$ This review article emphasizes on the fact that the decision to stop aspirin prior to dental surgery should depend on accurate medical history of the patient, laboratory tests to predict platelet function, invasiveness of surgical procedure and a discussion with the patient's physician.

\section{HISTORY OF ASPIRIN}

In 1899, a French chemist "Charles Frederic Gerhardt" was the first one who isolated and prepared aspirin and since then it was made commercially available. ${ }^{14}$ The name aspirin is derived from an "Acetyl" and Spirin from "Spirsa" ure," an old German name for salicylic acid. ${ }^{1}$ In 1950 , "Lawrence Craven" prescribed low-dose aspirin (baby aspirin) to his 400 patients and found that none of them developed myocardial infarction. 15

Financial or Other, Competing Interest: None.

Submission 25-11-2015, Peer Review 26-11-2015,

Acceptance 15-12-2015, Published 21-12-2015.

Corresponding Author:

Dr. Sumit Bhargava,

Associate Professor

Department of Anesthesia,

LN Medical College, Bhopal.

E-mail: roshanchanchlani@gmail.com

DOI:10.14260/jemds/2015/2516
This was probably the first time in medical history where aspirin was used to prevent myocardial infarction. Since then it has become the drug of choice for cardiologists. ${ }^{16}$

\section{BLOOD HOMEOSTASIS}

The blood is a fluid connective tissue and hemostatic mechanism is chiefly responsible for stopping the extravasation of blood in case of injury to the blood vessels. Hemostatic mechanisms are characterized by two consecutive phase. Primary hemostasis phase involving vascular and platelet mediated events that helps in early arrest of bleeding as a result of platelet plug formation. The secondary hemostasis phase is mediated by a complex cascade of clotting factors, which helps in the formation of fibrin clot. In normal physiological state, a perfect balance exists between coexisting interlinked mechanisms like coagulation/ anticoagulation and fibrinolysis/antifibrinolysis. Disturbance in the balance in favor of one mechanism results in either bleeding or thrombosis. ${ }^{17}$

\section{Mechanism of Action of Aspirin}

Aspirin has antiplatelet activity through inhibition of platelet aggregation. Aspirin irreversibly inactivates COX-1 activity by diffusing through the platelet membrane and binding to the catalytic pocket of the enzyme at arginine 120 residue. ${ }^{14}$ and acetylating the serine 529 residue. ${ }^{14,18,19}$ resulting in reduced formation of cyclic endoperoxides (Prostaglandin G2 and prostaglandin $\mathrm{H} 2$ ) and thromboxane A2.18,20,21,22 Platelet inhibition activity by aspirin begins at about 1 hour following ingestion. ${ }^{21,22}$ and it is irreversible lasting for the lifetime of the affected platelets (Around 7-10 days). ${ }^{20,21,22}$

\section{Pharmacokinetics}

Salicylic acid is a weak acid and very little of it is ionized in the stomach after oral administration. Aspirin is rapidly absorbed from the proximal intestine and stomach and converts to salicylate. It has peak circulating levels within 2 hours after ingestion. ${ }^{23}$ the half-life of salicylate is 2 to 15 hours depending on the dosage. ${ }^{3}$ 


\section{Medical Use}

Aspirin is used in the prevention and management of arterial and venous thrombosis in patients with ischaemic heart disease, previous myocardial infarction, coronary artery bypass, prosthetic heart valve, placement of a stent, nonhaemorrhagic stroke, transient ischaemic attacks, and peripheral arterial disease. ${ }^{24}$ Regular aspirin prophylaxis reduces the risk of nonfatal myocardial infarction by $30 \%$, nonfatal ischemic stroke by $30 \%$, and vascular death by about $17 \%$ in patients who are at high risk for atherosclerotic disease. ${ }^{25,26}$

\section{Dosage}

Aspirin is maximally effective as an antithrombotic agent at doses much lower than those required for anti-inflammatory and analgesic functions. ${ }^{27}$ recommended doses for asprin in the United States for the prevention of stroke and myocardial infarction are $81 \mathrm{mg}, 160 \mathrm{mg}$ and $325 \mathrm{mg}$ per day. In Europe and other countries $75 \mathrm{mg}, 150 \mathrm{mg}$ or $300 \mathrm{mg}$ per day are commonly recommended. ${ }^{28}$ The antiplatelet properties are effective up to $320 \mathrm{mg}$ daily dose.25 Doses of aspirin $>320 \mathrm{mg} /$ day may decrease the effectiveness as antiplatelet agent due to inhibition of prostacyclin production..$^{25}$ Low doses of aspirin (40mg/day. ${ }^{14}$ to $80 \mathrm{mg} /$ day..$^{10}$ ) can completely affect all the existing platelets. The optimal dose of aspirin for anti-platelet action as found by studies is $160 \mathrm{mg} /$ day. ${ }^{28}$ However, evidence suggests that low-dose aspirin (75-100mg daily) are generally indicated in cases of angina and ischemic heart disease, especially after coronary stenting following Myocardial Infarction (MI) and stroke. ${ }^{25,27}$ In emergency situations, such as in acute coronary syndromes a dose of 160 to $200 \mathrm{mg}(2,81$ mg uncoated baby aspirin) is recommended at the time of the episode to ensure the rapid inhibition of thromboxanedependent platelet aggregation. Uncoated aspirin should be used in emergencies, because it is absorbed immediately and antiplatelet activity is typical achieved within 40 minutes. Enteric-coated aspirin, in contrast can take up to 3 to 4 hours for peak blood levels. ${ }^{29}$

\section{Aspirin Resistance}

Aspirin resistance is defined as persistent platelet activation (i.e. incomplete platelet aggregation inhibition) occurring in individuals who take a therapeutic dose of aspirin. ${ }^{30}$ The mechanisms by which some patients are resistant to aspirin may involve polymorphisms in the COX-1 gene affecting arginine 120, serine 529 or both. Enhanced platelet regeneration and an increased proportion of newly formed platelets expressing COX-2 in response to chronic aspirin administration may cause resistance of platelets to inhibition by a low dose of aspirin. ${ }^{14}$ It has been found that aspirin resistance is partly reversible by increasing the dose of aspirin..$^{31}$

\section{Medical History}

Recording proper medical history is of vital importance when managing a patient on aspirin..$^{10}$ the dose and duration of aspirin use should be recorded. Assessment of co-morbid conditions such as liver disease, bone marrow disorders, biliary tract obstruction, malabsorption, renal disease, cancers (Leukemia) or increased inflammation of oral tissues should be done. ${ }^{3}$

\section{Aspirin And Periodontal Treatment}

The periodontal surgical procedures such as deep scaling, root planning, curretage, flap surgeries, etc. have high chances of bleeding when there is concurrent use of antiplatelet therapy. ${ }^{32}$ Bleeding On Probing (BOP) is widely interpreted as a sign of disease activity, whereas its absence is interpreted as both a sign and predictor of health. 33,34

Liede KE et al. in a study on 409 men, assessed the effect of alpha-tocopherol (Vitamin E) supplementation on gingival bleeding either in combination with Acetylsalicylic Acid (ASA) or without it. ASA alone increased bleeding only slightly. The highest risk of gingival bleeding was among those who took both alpha-tocopherol and ASA $33.4 \%$ of probed sites bleeding vs. $25.8 \%$ among subjects taking neither alphatocopherol nor ASA, P <0.001). They concluded that alphatocopherol supplementation may increase the risk of bleedings, particularly when combined with ASA. ${ }^{35}$

Schrodi $J$ et al. evaluated the effect of aspirin on the periodontal parameter bleeding on probing. A total of 46 period on tally healthy subjects were included in this study: 16 received placebo, 15 low-dose aspirin $(81 \mathrm{mg})$ and 15 regular dose $(325 \mathrm{mg})$ aspirin. Clinical parameters assessed included plaque index, periodontal probing depth and BOP using an automated pressure-sensitive probe. Measurements were recorded before and after 7-day exposure to placebo and aspirin regimens. Aspirin intake of $325 \mathrm{mg}$ daily for 7 days moderately increased the appearance of bleeding on probing in a population that had $>$ or $=20 \%$ BOP sites. ${ }^{34}$

Royzman D et al. studied the effect of aspirin intake on bleeding on probing in fifty-four patients with gingivitis. Patients were randomly assigned to one of three arms: placebo group, $81 \mathrm{mg}$ aspirin group or $325 \mathrm{mg}$ aspirin group. Before and after exposure to the respective regimens, clinical parameters were measured on all the teeth: the plaque index was recorded at four sites per tooth and probing depth and BOP were evaluated at six sites per tooth using an automated pressuresensitive probe, the results showed that "Low dose" 81mg and "Regular dose" $325 \mathrm{mg}$ of aspirin demonstrated a statistically significant $5.30(\mathrm{P}=0.001)$ and $4.13(\mathrm{P}=0.010)$ increase from baseline respectively, in percent BOP. ${ }^{33}$ According to Yoshinari Morimoto et al. scaling can be safely performed in patients on warfarin (INR _4.0) and/or antiplatelet therapy. ${ }^{36}$

\section{Aspirin and Oral Surgical Treatment}

Nasser Nooh conducted a study on one hundred and eightynine subject to determine if ASA was associated with bleeding after dental extraction. The results showed that bleeding after $24 \mathrm{hr}$. was seen in patients with ASA who underwent surgical extraction. He concluded that patients receiving 81mg of ASA daily could undergo dental extraction without bleeding risks. ${ }^{1}$ Park M. W. et al. performed dental extractions in patients who had undergone coronary stenting and who were also on oral multiple antiplatelet agents therapy; 100 patients underwent dental procedures without stopping antiplatelet agents. Control group consisted of 2233 patients who had not taken oral antiplatelet agents and had teeth extracted by the same method. There were 2 excessive intra-extraction bleeding cases that continued at the extraction site for 4 and 5 hours, respectively in the coronary stenting patients. While one excessive intra-extraction bleeding case was noticed, that continued for 3 hours in the control patients. 
They concluded that most dental extractions in coronary stenting patients can be carried out safely without stopping multiple antiplatelet agents. ${ }^{37}$ Bajkin B.V. et al. conducted a prospective clinical study by performing simple dental extractions on 43 patients taking 2 anti-platelet drugs, mostly aspirin and clopidogrel and 117 patients taking a single antiplatelet drug in the form of aspirin, clopidogrel and ticlopidine. Bleeding was recorded after extraction in only one patient on dual aspirin-clopidogrel treatment, which was mild and easily controlled by local haemostasis. They concluded that patients taking single or dual antiplatelet drugs may have teeth extracted safely without interruption of treatment using only local haemostatic measures. ${ }^{24}$

In the prospective study by Broekema F.I. et al., 206 patients were evaluated for the incidence of bleeding after dentoalveolar operations, where 103 subjects took anticoagulants and rest 103 did not take anticoagulants. Seventy-one were taking thrombocyte aggregation inhibitors and 32 vitamin $\mathrm{K}$ antagonists. The operations studied included surgical extraction (When the surgeon had to incise the gingiva before extraction), non-surgical extraction, apicectomy and placement of implants. No patient developed a severe bleed that required intervention. All bleeding was controlled by the patients themselves with compression with gauze. They concluded that dentoalveolar surgery is safe in patients being treated with anticoagulants provided that the conditions described in the ACTA guidelines are met. ${ }^{38}$

Darawade D.A. et al. evaluated the influence of aspirin on post-extraction bleeding in a clinical setup of 200 patients randomly divided into aspirin continuing group (Group A) and aspirin discontinuing group (Group B). They concluded that there is absolutely no need to discontinue antiplatelet therapy for any ambulatory dental procedure and even if the practitioner wishes to discontinue it should not be for more than 3 days. This is also stated in the guidelines of the American Heart Association. ${ }^{16}$

Lillis $\mathrm{T}$ et al. recruited 643 consecutive patients referred for dental extractions. In total 111(17.3\%) were on clinically indicated antiplatelet therapy: aspirin ( $\left.n_{-} 42\right)$, clopidogrel ( _ 36), and aspirin and clopidogrel ( $n_{-}$33). Controls ( $n_{-} 532$, $82.7 \%$ ) were not on antiplatelet treatment. Immediate and late bleeding complications were recorded. Compared to controls the risk of prolonged immediate bleeding was higher in patients on dual antiplatelet therapy, but not in patients on aspirin alone or clopidogrel alone. However, all immediate bleeding complications in all treatment groups were successfully managed with local hemostatic measures. They concluded that dental extractions may be safely performed in patients receiving single or dual antiplatelet therapy when appropriate local hemostatic measures are taken. ${ }^{39}$

Francisco C.T. et al. conducted a trial on 155 patients who underwent dental extractions and were receiving antiplatelet therapy. No major haemorrhages were reported. One patient had a moderate haemorrhage that required emergency care. In the remaining patients, the bleeding was controlled with local measures. It can be concluded that no more than 3 teeth should be removed at any one time and for multiple extractions the teeth should be adjacent to each other. ${ }^{40}$

Ardekian L et al. conducted a study on 39 patients who were scheduled to undergo dental extractions. All patients were receiving 100 milligrams of aspirin daily on a regular basis.
The authors randomly divided the patients into two groups: Those who stopped the aspirin therapy before the procedure and those who continued the aspirin therapy. The mean $(+/$ - standard deviation) bleeding time was $1.8+/-0.47$ minutes for patients who stopped aspirin therapy one week before the procedure. For patients who continued aspirin therapy, the bleeding time was 3.1+/-0.65 minutes. No episodes of uncontrolled intraoperative or postoperative bleeding were noted. The authors concluded by saying that low-dose aspirin therapy should not be stopped before oral surgery. Local hemostasis is sufficient to control bleeding. ${ }^{41}$

The study by Madan G.A. et al. included 51 patients who underwent minor oral surgical procedures. Aspirin was not stopped for a single patient. There was no excessive intraoperative bleeding in all cases except one; there was no postoperative bleeding in all cases. They concluded that most minor oral surgery procedures can be carried out safely without stopping long-term low-dose aspirin regimen. ${ }^{42}$

A prospective observational study was done by Partridge C.G. et al. which quantitatively assessed the amount and severity of bleeding encountered with dentoalveolar surgery in 2 groups. The experimental group consisted of people taking therapeutic doses of platelet-altering medications and the control group was composed of patients who did not take platelet-altering medication for at least 10 days prior to surgery. There was no difference in blood loss detected between the experimental or control groups. No bleeding complications were encountered. The authors suggested that patients on aspirin and NSAIDs can safely undergo outline minor outpatient oral surgical procedures without modification of their platelet-altering medication. ${ }^{43}$

Brennan M.T. et al. conducted a study on 36 healthy persons requiring a tooth extraction by randomizing them to receive $325 \mathrm{mg}$ /day aspirin or placebo for 4 days. Cutaneous Bleeding Time (BT) and platelet aggregation tests were obtained prior to extraction. The primary outcome measure, oral BT and secondary bleeding outcomes were evaluated during and following extraction. There were no differences in oral BT, cutaneous BT, secondary outcome measures or compliance. Whole-blood aggregation results were significantly different between the aspirin and placebo groups. These findings suggest that there is no indication to discontinue aspirin for persons requiring single-tooth extraction. ${ }^{44}$

Balasubramanian K. et al. in their study on 82 patients requiring dental extractions. Patients were divided into 3 groups. Group 1 consisted of patients in whom antiplatelet therapy was interrupted ( $n=25)$, group 2 consisted of those continuing their medication $(n=32)$ and group 3 comprised healthy patients not on antiplatelet therapy $(n=25)$. Results showed that the mean bleeding times in groups 1,2 and 3 were 3 minutes, 2 minutes and 45 seconds and 1 minute and 49 seconds respectively. The mean clotting times in groups 1,2 and 3 were 5 minutes and 4 seconds, 4 minutes and 52 seconds, and 3 minutes and 42 seconds respectively. No patient in any group had any episode of prolonged or significant bleeding from the extraction sites. The authors concluded that routine dental extractions can be safely performed in patients on long-term antiplatelet medication with no interruption or alteration of their medication. ${ }^{45}$

Frederico B.M. et al. conducted a study on 63 patients with coronary artery disease who required tooth extraction. 
Patients were randomly placed into 2 groups: group $\mathrm{S}$, which was comprised of patients whose ASA therapy was suspended 7 days before tooth extraction and group NS, comprised of patients whose ASA therapy was unaltered. A platelet aggregation test was carried out on the day of the operation and the amount of bleeding was measured during the intraoperative period by means of aspirated blood collection. There was no difference in the amount of bleeding that occurred during tooth extraction between patients who continued ASA therapy versus patients who suspended their ASA therapy. The platelet reactivity test demonstrated a reduction in platelet aggregation in the ASA therapy group (Group NS), but this reduction was without clinical consequence. ${ }^{46}$

Bajkin B.V. et al. in a study on 213 patients evaluated the effects of combined oral anticoagulant-aspirin therapy in patients undergoing tooth extractions. Patients were divided into three groups of 71 participants each. Patients in group A received combined anticoagulant-aspirin (100-milligram prophylactic dose) therapy. Patients in group B received oral anticoagulant therapy. Patients in group $\mathrm{C}$ received aspirin therapy (100-mg prophylactic dose). Bleeding was marked as an "Event" if it met the following criteria: the bleeding continued beyond 12 hours, patient had to call the surgeon or return to dental practice or emergency department, bleeding resolved with large hematoma or ecchymosis within the oral soft tissues or required a blood transfusion. The authors found no statistical significance in postoperative bleeding between these three groups. All cases of hemorrhage were controlled easily by using local hemostatic measures. ${ }^{47}$

Tom Dodson conducted a study on patients with coronary artery disease. Patients were randomized to either having their ASA therapy suspended for seven days before tooth extraction and restarted the day following the surgical procedure or not having their ASA therapy suspended at any point before or after the procedure. Bleeding was controlled with local haemostatic methods and there were no reported episodes of haemorrhaging during the intra- and post-

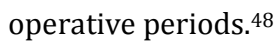

Wang W.Y. et al. conducted a study to evaluate the influence of aspirin on post-operative bleeding after tooth extraction in 300 elderly subjects: 200 patients without using aspirin before tooth extraction served as control group I, 100 patients with prolong use of aspirin before tooth extraction as observation group I. 300 elderly outpatients used compound articaine local infiltration anesthesia, 200 patients without using aspirin before tooth extraction served as control group II, 100 patients with prolong use of aspirin before tooth extraction as observation group II. There was no significant difference at 5, 10, $30 \mathrm{~min}, 24 \mathrm{~h}$ in postoperative bleeding after extraction between control group I and observation group. The incidence of bleeding of observation group II after tooth extraction at 5 min was higher than that of control group II and there was no significant difference at $10,30 \mathrm{~min}, 24 \mathrm{~h}$ between the two groups. The authors concluded that continuation of aspirin have no influence on postoperative bleeding. 49

\section{Importance of Laboratory Tests}

Importance of laboratory tests to detect platelet function in patients on aspirin is questionable. Commonly advised laboratory tests to measure platelet function in patients on aspirin include the Bleeding Time Test (BT).1,40,50 Platelet count. ${ }^{37}$ Prothrombin Time (PT). ${ }^{37}$

Partial Thromboplastin Time (PTT). ${ }^{37}$ Platelet Function Analyzer (PFA)-100.40 Platelet Aggregation Measurement. ${ }^{40,14}$ Multiple Electrode Aggregometry (MEA). ${ }^{18}$ BT test predicts the degree of interference with platelet function from aspirin and therefore predict the risk of bleeding from these drugs during and after an oral surgical procedure. ${ }^{50}$ The PFA-100 is often used to establish the presence of absence of aspirin resistance. The frequency of aspirin resistance is unknown, but estimates range from $5-60 \% .^{50}$ The platelet aggregation (Impedance) test is more sensitive and determines the adequacy of platelet responsiveness to physiologic stimuli such as collagen, arachidonic acid and adenosine diphosphate. As little as $81 \mathrm{mg}$ of aspirin will impede aggregation by this test. ${ }^{51}$

Multiple Electrode Aggregometry (MEA) is a newly developed technique for testing platelet function in whole blood based on classic whole-blood impedance aggregometry. MEA does not require a specialized coagulation laboratory and may be useful for point-of-care analysis.52 According to Aframian D.J. et al. laboratory monitoring is not typically recommended for patients taking aspirin. ${ }^{3}$ Brenan et al. have indicated there is no analytical test which serves to conclusively evaluate the risk of bleeding in patients on aspirin. ${ }^{14}$ The bleeding time test is not at all useful to assess oral bleeding after invasive dental procedures. ${ }^{3} \mathrm{~A}$ pilot study of 30 patients undergoing dental extraction showed that cutaneous bleeding time did not correlate with oral bleeding time or any measures of postoperative hemostasis. 50

According to Park M. W. et al. if the patient's platelet count is over $100,000 / \mathrm{mm} 3$, it is recommended that patients should not stop antiplatelet agents for 7 days and not delay dental extraction after coronary stenting. ${ }^{37}$ Lockhart P.B. et al. states that the platelet count or measure of the number of platelets in the systemic circulation, gives no information concerning their viability or functionality. ${ }^{10}$

\section{Dual Antiplatelet Therapy}

Antiplatelet agents can be classified by their mode of action in prevention of platelet activation and aggregation. ${ }^{4}$ ASA (Aspirin) and triflusal work through inactivation of the enzyme cyclooxygenase.21,22 Thienopyridines (e.g., Clopidogrel, Ticlopidine and Prasugrel) irreversibly inhibit adenosine diphosphate, which is necessary for the activation of the receptor GPIIb/IIIa complex in platelet aggregation. $.3,20$ Drugs targeted directly to the GPIIb/IIIa complex include tirofiban, eptibatide and abciximab. ${ }^{35}$ Dipyridamole and cilostazol are phosphodiesterase inhibitors that decrease platelet aggregability. ${ }^{35}$ In addition, tocopherol (vitamin E) has been shown to inhibit platelet adhesion to the adhesive proteins collagen, fibrinogen and fibronectin. 35

These drugs are sometimes combined, because they work in different ways. ${ }^{24}$ Thienopyridines (cCopidogrel or Ticlopidine), in combination with aspirin therapy have been shown to dramatically reduce the incidence of early major adverse cardiac events after stent placement. ${ }^{44}$ Uninterrupted dual antiplatelet therapy is currently recommended in patients with drug-eluting stents who undergo dental procedures. $^{39}$ 


\section{Adverse Effects With Dual Antiplatelet Drug Discontinution}

The leading adverse event associated with early antiplatelet discontinuation is stent thrombosis, and the majority of these events lead to acute myocardial infarction (MI) or death. ${ }^{12,55}$ Reported mortality from presumed or documented thrombosis ranges from $20 \%$ to $45 \% .^{55}$ Stent thrombosis most commonly occurs in the first month after stent implantation and in this interval it is referred to as "Subacute stent thrombosis." However, numerous cases of "late stent thrombosis," particularly in patients who have been treated with DES have been described as occurring months or even years after stent implantation. ${ }^{56}$

\section{Evidence of a Rebound In Platelet Activity following Aspirin Withdrawal}

Early thromboembolic complications have been reported after the interruption of treatment in patients who required aspirin for prevention of ischemic vascular disease. ${ }^{57}$ Interruption of aspirin therapy is associated with a progressive recovery of platelet function and therefore with a potential rebound of thrombotic arterial events. The average time delay between single oral antiplatelet therapy interruption and rebound of thrombotic events is 11 days. Because this time delay corresponds to platelet half-life and therefore to platelet functional recovery after interruption, it is assumed that there is a causal relationship between interruption and acute vascular events. ${ }^{58}$ Aspirin withdrawal is associated with a "Rebound" phenomenon that is prothrombotic and/or proinflammatory and plays a causative role in adverse events. This rebound hypothesis, as a scientific entity, can be defined as an increase in platelet reactivity following aspirin withdrawal to a level exceeding that at baseline prior to initiation of aspirin therapy. ${ }^{59}$ A study assessed whether aspirin cessation resulted in a "Rebound" phenomenon of platelet hyper-aggregation or merely a recovery of normal platelet function; 11 participants were given aspirin for one week (300mg loading dose on day 1, 150mg on days 2-7). Blood sampling was performed in all subjects at baseline (Before the first dose of aspirin therapy), and at days 7 (The day of the last dose of aspirin therapy), 14 and 21. However, they found no evidence of a rebound increase in platelet functional activity following cessation of aspirin. 60

\section{When to Stop Aspirin Prior to Invasive Dental Procedures}

Traditionally, it is recommended to stop aspirin therapy 7-10 days prior to surgery since platelet inhibition by aspirin begins at about 1 hour following ingestion and lasts for the lifetime of the affected platelets (Around 7-10 days). ${ }^{61,21,22}$

According to Daniel et al. antiplatelet therapy should be stopped 7 days preoperatively to minimize the risk of bleeding during surgery. ${ }^{62}$ Sonksen et al. performed a clinical study on 52 healthy volunteers taking 7-day course of low-dose aspirin. They found that after stopping the aspirin the Bleeding Time (BT) was less than 10 minutes within 48 hours of stopping the aspirin therapy. Hence, they stated that withdrawal of aspirin for $\geq 5$ days appears erroneous. ${ }^{63}$ Current French guidelines on preoperative antiplatelet drug management, which are based solely on expert opinion recommend that aspirin be withdrawn three to five days before high-bleeding-risk procedures. ${ }^{64}$ Darawade D.A. et al. evaluated the influence of aspirin on post-extraction bleeding in a clinical setup of 200 patients randomly divided into aspirin continuing group (Group A) and aspirin discontinuing group (Group B).

They concluded that there is absolutely no need to discontinue antiplatelet therapy for any ambulatory dental procedure and even if the practitioner wishes to discontinue, it should not be for more than 3 days. ${ }^{16}$ Wahl et al. advocated that aspirin should be discontinued for 3 days only, as after 3 days of interruption of aspirin, sufficient number of newer platelets would be present in the circulation for hemostasis. 65

According to Jeonghun Lee et al. the platelet function generally recovers if the aspirin cessation period exceeds 96 hours. Thus a shorter aspirin intake cessation period [4 days] may be allowable in complex dental procedures and surgery for which a longer aspirin intake cessation period (7-10 days) is recommended based on the American College of Chest Physician's guidelines. ${ }^{18}$

Aframian et al. recommend that low-dose aspirin therapy (100mg per day or less) should not be interrupted for outpatient dental procedures. Because the benefit to patients (Preventing a thromboembolic episode) clearly outweighs the risk (Bleeding episode), this is a class I recommendation. ${ }^{3}$

According to Park et al. if the patient's platelet count is over $100,000 / \mathrm{mm} 3$, they would recommend that patients would not stop antiplatelet agents for 7 days and not delay dental extraction after coronary stenting. ${ }^{37}$

Joel J. Napeñas, support the recommendation that there is no indication to alter or stop anti-platelet drugs and that local hemostatic measures are sufficient to control bleeding. ${ }^{4}$

Current American College of Cardiology/American Heart Association/Society for Cardiovascular Angiography and Interventions recommendations for the prevention of stent thrombosis after coronary stent implantation state that at a minimum, patients should be treated with clopidogrel $75 \mathrm{mg}$ and aspirin $325 \mathrm{mg}$ for 1 month after bare-metal stent implantation, 3 months after sirolimus Drug Eluting Stent (DES) implantation, 6 months after paclitaxel DES implantation, and ideally up to 12 months if they are not at high risk for bleeding. ${ }^{66}$ These recommendations were based on the antiplatelet regimen used in trials that were conducted to obtain US Food and Drug Administration approval (Lowrisk lesions in low-risk patients) and the anticipated time it takes for the metal stent struts to become adequately endothelialized to reduce the risk of stent thrombosis. ${ }^{55}$

\section{CONCLUSION}

From the above review of literature, we would like to conclude that the practice of blindly discontinuing aspirin therapy prior to dental extraction should be avoided. Accurate medical history of the patient should be recorded, laboratory tests to predict platelet function should be performed, invasiveness of surgical procedure should be assessed and a discussion with the patient's physician should be done.

\section{REFERENCES}

1. Nooh N. The effect of aspirin on bleeding after extraction of teeth. The Saudi Dental Journal 2009;21:57-61.

2. Patrono C, Rocca B. Drug insight: aspirin resistance-fact or fashion? Nat Clin Pract Cardiovasc Med 2007;4:42-50.

3. Aframian DJ, Lalla RV, Peterson DE. Management of dental patients taking common hemostasis altering medications. Oral Surg Oral Med Oral Pathol Oral Radiol Endod 2007;103(suppl 1):S45.e1-S45.e11. 
4. Napeñas JJ, Oost FCD, De Groot A, Loven B, Hong CHL, Brennan MT, et al. Review of postoperative bleeding risk in dental patients on antiplatelet therapy. Oral Surg Oral Med Oral Pathol Oral Radiol 2013;115:491-499.

5. Wahl MJ. Dental surgery in anticoagulated patients. Arch Intern Med 1998;158:1610-1616.

6. Biondi-Zoccai GG, Lotrionte $\mathrm{M}$, Agostoni $\mathrm{P}$, et al. A systematic review and meta-analysis on the hazards of discontinuing or not adhering to aspirin among 50279 patients at risk for coronary artery disease. Eur Heart J 2006;27:2667-74.

7. Burger W, Chemnitius JM, Kneissl GD, et al. Low-dose aspirin for secondary cardiovascular preventioncardiovascular risks after its perioperative withdrawal versus bleeding risks with its continuation- review and meta-analysis. J Intern Med 2005;257:399-414.

8. Ferrari E, Benhamou M, Cerboni $\mathrm{P}$, et al. Coronary syndromes following aspirin withdrawal: a special risk for late stent thrombosis. J Am Coll Cardiol 2005;45:456-9.

9. Maulaz AB, Bezerra DC, Michel P, et al. Effect of discontinuing aspirin therapy on the risk of brain ischaemic stroke. ArchNeurol 2005;62:1217-20.

10. Lockhart PB, Gibson J, Pond SH, et al. Dental management considerations for the patient with an acquired coagulopathy. Part 2: coagulopathies from drugs. Br Dent J 2003;195:495-501.

11. Oake N, Jennings A, Forster AJ, Fergusson D, Doucette $S$, Walraven, et al. Anticoagulation intensity and outcomes among patients prescribed oral anticoagulant therapy: a systematic review and meta-analysis. CMAJ 2008;179:23544.

12. Collet JP, Himbet F, Steg PG. Myocardial infarction after aspirin cessation in stable coronary artery disease patients. Int J Cardiol 2000;76(2-3):257-8.

13. Kaluza GL, Joseph J, Lee JR, et al. Catastrophic outcomes of non-cardiac surgery soon after coronary stenting. J Am Coll Cardiol 2000;35:1288-94.

14. Brennan MT, Wynn RL, Miller CS. Aspirin and bleeding in dentistry: an update and recommendations. Oral Surg Oral Med Oral Pathol Oral Radiol Endod 2007;104:316-23.

15. Craven LL. Acetylsalicylic acid, possible preventive of coronary thrombosis. Ann West Med Surg 1950;4:95.

16. Darawade DA, Kumar S, Desai K, et al. Influence of aspirin on post-extraction bleeding - A clinical study J Int Soc Prev Community Dent 2014;4(1):S63-S67.

17. Cãnigral A, Silvestre F-J, Cãnigral G, Al'os M, GarciaHerraiz A, Plaza A. Evaluation of bleeding risk and measurement methods in dental patients. Med Oral Patol Oral Cir Bucal 2010;15(6):e863-8.

18. Lee J, Kim JK, Kim JH, Dunuu T, Park SH, Park SJ, et al. Recovery time of platelet function after aspirin withdrawal. Current Therapeutic Research 2014;76:26-31.

19. Maree AO, Fitzgerald DJ. Variable platelet response to aspirin and clopidogrel in atherothrombotic disease circulation. 2007;115:2196-2207.

20. North West Medicines Information Centre. Surgical management of the primary care dental patient on antiplatelet medication. North West Medicines Information Centre; 2010. Available at: http://ukmi.nhs.uk/activities/specialist Services.
21. George JN, Shattil SJ. The clinical importance of acquired abnormalities of platelet function. $N$ Engl J Med 1991;324:27-39.

22. Vane JR, $A "$ nggård EE, Botting RM. Regulatory functions of the vascular endothelium. N Engl J Med 1990;323:27-36.

23. Owens CD, Belkin M. Thrombosis and coagulation: operative management of the anticoagulated patient. Surg Clin North Am 2005;85(6):1179-89.

24. Bajkin BV, Urosevic IM, Stankov KM, et al. Dental extractions and risk of bleeding in patients taking single and dual antiplatelet treatment. British Journal of Oral and Maxillofacial Surgery 2015;53:39-43.

25. Antithrombotic Trialist's Collaboration. Collaborative meta-analysis of randomised trials of antiplatelet therapy for prevention of death, myocardial infarction and stroke in high risk patients. BMJ 2002;324:71-86.

26. Collaborative overview of randomised trials of antiplatelet therapy- I: Prevention of death, myocardial infarction and stroke by prolonged antiplatelet therapy in various categories of patients. Antiplatelet Trialists' Collaboration. BMJ 1994;308:81-106.

27. Patrono C, Ciabarroni G, Patrignani P, et al. Clinical pharmacology of platelet cyclo-oxygenase inhibition, Circulation 1985;72(6):1177-1184.

28. Dalen JE. Aspirin to prevent heart attack and stroke: what's the right dose? Am J Med 2006;119(3):198-202.

29. Patrono C, Coller B, FitzGerald GA, et al. Platelet active drugs: the relationships among dose, effectiveness and side effects: the Seventh ACCP Conference on Antithrombotic and Thrombolytic Therapy. Chest 2004; 126:234S-264S.

30. Sanderson S, Emery J, Baglin T, et al. Narrative review: aspirin resistance and its clinical implications. Ann Intern Med 2005;142:370-80.

31. Helgason CM, Bolin KM, Hoff JA, Winkler SR, Mangat A, Tortorice KL, et al. Development of aspirin resistance in persons with previous ischemic stroke. Stroke 1994;25:2331-6.

32. Chee FY, How CH. Doctor, my dentist wants your opinion. Singapore Med J 2013;54(1):11-4.

33. Royzman D, Recio L, Badovinac RL, et al. The effect of aspirin intake on bleeding on probing in patients with gingivitis. Journal of Periodontology 2004;75(5):679-684.

34. Schrodi J, Recio L, Fiorellini J, Howell H, Goodson M, Karimbux N, et al. The effect of aspirin on the periodontal parameter bleeding on probing. Journal of Periodontology, 2002;73(8):871-76.

35. Liede KE, Haukka JK, Saxén LM, et al. Increased tendency toward gingival bleeding caused by joint effect of alphatocopherol supplementation and acetylsalicylic acid. Ann Med 1998;30:542-6.

36. Morimoto $\mathrm{Y}$, Niwa $\mathrm{H}$, Minematsu $\mathrm{K}$, et al. Hemostatic management of tooth extractions in patients on oral antithrombotic therapy. Journal of Oral and Maxillofacial Surgery 2008;66(1):51-57.

37. Park MW, Her SH, Kwon JB, et al. "Safety of dental extractions in coronary drug-eluting stenting patients without stopping multiple antiplatelet agents." Clinical Cardiology 2012;35(4):225-230. 
38. Broekema FI, Van Minnen B, Jansma J, et al. Risk of bleeding after dentoalveolar surgery in patients taking anticoagulants. British Journal of Oral and Maxillofacial Surgery 2014;52:e15-e19.

39. Lillis T, Ziakas A, Koskinas $\mathrm{K}$, et al. Safety of dental extractions during uninterrupted single or dual antiplatelet treatment, American Journal of Cardiology 2011;108(7):964-67.

40. Tortajada FC, G'omez ES, Garmendia JF, et al. Dental extractions in patients on antiplatelet therapy. A study conducted by the Oral Health Department of the Navarre Health Service (Spain), Med Oral Patol Oral Cir Bucal 2009;14(11):e588-92.

41. Ardekian L, Gaspar R, Peled M, et al. Does low-dose aspirin therapy complicate oral surgical procedures? J Am Dent Assoc 2000 Mar;131(3):331-5.

42. Madan GA, Madan SG, Madan G, et al. Minor oral surgery without stopping daily low-dose aspirin therapy: a study of 51 patients, Journal of Oral and Maxillofacial Surgery 2005;63(9):1262-65.

43. Partridge CG, Campbell JH, Alvarado F, et al. "The effects of platelet-altering medications on bleeding from minor oral surgery procedure." Journal of oral and maxillofacial surgery 2008;66(1):93-97.

44. Brennan MT, Valerin MA, Noll JL, et al. "Aspirin use and post-operative bleeding from dental extractions." Journal of Dental Research 2008;87(8):740-744.

45. Krishnan B, Shenoy NA, Alexander M. Exodontia and Antiplatelet Therapy. J Oral Maxillofac Surg 2008 Oct;66(10):2063-6.

46. Medeiros FB, de Andrade AC, Angelis GA, et al. Bleeding evaluation during single tooth extraction in patients with coronary artery disease and acetylsalicylic acid therapy suspension: a prospective, double-blinded and randomized study. J Oral Maxillofac Surg 2011 Dec;69(12):2949-55.

47. Bajkin BV, Bajkin IA, Petrovic BB, et al. The effects of combined oral anticoagulant-aspirin therapy in patients undergoing tooth extractions: a prospective study. Journal of the American Dental Association, vol. 143, no. 7, pp. 771-776, 2012.

48. Dodson T. Should Acetylsalicylic Acid (ASA) therapy for prevention of thromboembolic events be stopped prior to surgical extractions? Evidence-Based Dentistry 2012;13:89-90.

49. Wang WY, Cui NH, Wang EB, et al. Clinical evaluation of influence of aspirin on post-operative bleeding after tooth extraction in the elderly. Zhonghua Kou Qiang Yi Xue Za Zhi. 2013 May;48(5):262-

50. Brennan MT, Shariff G, Kent ML, et al. Relationship between bleeding time test and post-extraction bleeding in a healthy control population. Oral Surg Oral Med Oral Pathol Oral Radiol Endod 2002;94:439-43.

51. Malhotra S. ${ }^{1}$, Sharma YP, Grover A, et al. Effect of different aspirin doses on platelet aggregation in patients with stable coronary artery disease. Intern Med J. 2003 Aug;33(8):350-4.

52. Sibbing D, Braun S, Jawansky S, et al. Assessment of ADPinduced platelet aggregation with light transmission aggregometry and multiple electrode platelet aggregometry before and after clopidogrel treatment. Thrombosis and Haemostasis 2008;99(1):121-126.

53. Merritt JC, Bhatt DL. The efficacy and safety of perioperative antiplatelet therapy. J Thromb Thrombolysis 2002;13:97-103.
54. Ten Berg JM, Plokker H, Verheugt F. Antiplatelet and anticoagulant therapy in elective percutaneous coronary intervention. Curr Control Trials Cardiovasc Med 2001;2:129-140.

55. Grines CL, Bonow RO, Casey DE, Jr, et al. Prevention of premature discontinuation of dual antiplatelet therapy in patients with coronary artery stents: a science advisory from the American Heart Association, American College of Cardiology, Society for Cardiovascular Angiography and Interventions, American College of Surgeons and American Dental Association with representation from the American College of Physicians, Circulation 2007;115(6):813-818.

56. Pfisterer M, Rocca HPB, Buser PT, et al. Late clinical events after clopidogrel discontinuation may limit the benefit of drug-eluting stents an observational study of drug-eluting versus bare-metal stents. Journal of the American College of Cardiology 2006;48(12):2584-91.

57. Lordkipanidzé M, Diodati JG, Pharand C. Possibility of a rebound phenomenon following antiplatelet therapy withdrawal: A look at the clinical and pharmacological evidence. Pharmacology \& Therapeutics 2009;123:178-186.

58. Collet JP and Montalescot G. Premature withdrawal and alternative therapies to dual oral antiplatelet therapy European Heart Journal Supplements 2006; 8 (Supplement G): G46-G52.

59. Sambu N, Warner T, Curzen N. Clopidogrel withdrawal: Is there a "Rebound" phenomenon? Thromb Haemost 2011;105:211-220.

60. Alcock RF, Reddel CJ, Pennings GJ. The rebound phenomenon after aspirin cessation: The biochemical evidence. International Journal of Cardiology 2014;174:376-463.

61. Kumar J, Kumari MM, Arora N, et al. "Is antiplatelet therapy interruption a real clinical issue? Its implications in dentistry and particularly in periodontics." Journal of Indian Society of periodontology, vol. 13, no. 3, pp. 121125, 2009.

62. Daniel NG, Goulet J, Bergeron M. Antiplatelet Drugs: Is There a Surgical Risk? J Can Dent Assoc 2002;68 (11): 683-7.

63. Sonksen JR, Kong KL and Holder R. Magnitude and time course of impaired primary haemostasis after stopping chronic low and medium dose aspirin in healthy volunteers. British Journal of Anaesthesia 1999;82(3):360-365.

64. Perioperative management of antiplatelet agents in patients with coronary stents: recommendations of a French Task Force. British Journal of Anaesthesia 97(4):580-5; (2006).

65. Wahl MJ. Myths of dental surgery in patients receiving anticoagulant therapy. J Am Dent Assoc 2000 Jan;131(1):77-81.

66. Smith SC Jr, Feldman TE, Hirshfeld JW Jr, Jacobs AK, Kern MJ, King SB III, et al. ACC/AHA/SCAI 2005 guideline update for percutaneous coronary intervention: a report of the American College of Cardiology/America Heart Association Task Force of Practice Guidelines (ACC/AHA/SCAI Writing Committee to update the 2001 Guidelines for Percutaneous Coronary Intervention). 2005. Available at: http://www.americanheart. Org/presenter.jhtml? identifier_30354. 